\title{
SOCIOLOGIAS INDÍGENAS IORUBA: A ÁFRICA, O DESCONCERTO E ONTOLOGIAS NA SOCIOLOGIA CONTEMPORÂNEA ${ }^{1}$
}

\author{
Yoruba indigenous sociologies: Africa, disconcertment and \\ ontologies in contemporary sociology \\ Sociologías indígenas yorubas: África, desconcierto y ontologías \\ en la sociología contemporánea
}

MARCELO C. ROSA $\mathrm{I}^{*}$

DOI: http://dx.doi.org/10.1590/S2178-14942019000200004

\footnotetext{
${ }^{1}$ Texto originalmente apresentado no $42^{\circ}$ Encontro Anual da Assosiação Nacional de Pós-Graduação e Pesquisa em Ciências Sociais (Anpocs). A versão submetida à revista se beneficia dos comentários críticos do Grupo de Trabalho Teoria Social: Agendas, Desafios e Perspectivas. Agradeço às integrantes do Laboratório de Sociologia Não Exemplar da Universidade de Brasília (UnB), a Antonádia Borges, por sua atenta leitura, e aos pareceristas anônimos. A pesquisa foi realizada com recursos do Centro Nacional de Desenvolvimento Científico e Tecnológico (CNPq).

' Universidade de Brasília (UnB), Brasília - DF, Brasil.

*Professor do Departamento de Sociologia da UnB e pesquisador bolsista de Produtividade em Pesquisa do CNPq. (marcelocr@gmail.com). ORCID iD: http://orcid.org/0000-0001-8535-9570

Artigo recebido em 9 de março de 2019 e aceito para publicação em 05 de julho de 2019.
} 


\title{
RESUMO
}

O texto busca reconstruir a história e a recepção internacional do debate africano centrado na noção de sociologias indígenas, liderado por Akinsola Akiwowo, no âmbito da Associação Internacional de Sociologia. Para além de reconstituir os passos do próprio autor na construção e na apresentação de seu argumento, busca-se também reconstruir os sentidos de sua interpretação nas discussões dominantes sobre teoria e geopolítica sociológica. Os dois principais polos interpretativos seriam a constatação crítica de seu caráter ideográfico e limitado em termos conceituais, de um lado, e a defesa geopolítica de sua importância por ter origem fora da Euroamérica, de outro. Nenhuma das tendências considera, porém, o projeto bem-sucedido. Como conclusão, o texto propõe que uma leitura mais profícua da contribuição das "sociologias indígenas" para a sociologia global se daria por meio de seu reconhecimento como alternativa teórico-metodológica para a expansão do universo ontológico do pensamento sociológico contemporâneo.

PALAVRAS-CHAVE: Teoria social; Sociologias indígenas; Teorias do sul, Sociologias do sul; Sociologia africana; loruba.

\begin{abstract}
The paper aims to reconstruct the history and international reception of the African debates on the "indigenous sociologies" lead by Akinsola Akiwowo in the International Sociological Association congresses and publications. The reconstitution of its reception in the debates framed under the association of theory and geopolitics demonstrate a polarization between: a) a critical appraisal of the limits of a supposed ideographic conceptual construction; b) a geopolitical defense of initiative since it was assembled outside de Euro-Americas. Both perspectives though tend to consider Akiwowo's project as a failure for different reasons. The conclusion offers an alternative interpretation of the contribution based on the reading of the project as a theoretical-methodological expansion of the available ontological universe of the hegemonic sociological thought.
\end{abstract}

KEYwORDS: Social theory; Indigenous sociologies; Southern Theories, Sociologies of the South; African sociology; Yoruba.

\section{RESUMEN}

El texto busca reconstruir la historia y la recepción internacional del debate africano centrado en la noción de sociologías indígenas, liderado por Akinsola Akiwowo, en el marco de la Asociación Internacional de Sociología. Además de reconstituir los propios pasos del autor en la construcción y presentación de su argumento, también se busca reconstruir los significados de su interpretación en las discusiones dominantes sobre teoría sociológica y geopolítica. Los dos polos interpretativos principales serían la observación crítica de su carácter ideográfico y limitada en términos conceptuales, por un lado, y la defensa geopolítica de su importancia porque se origina fuera de Euroamérica, por el otro. Ninguna de las tendencias, sin embargo, considera el proyecto exitoso. Como conclusión, el texto propone que una lectura más fructífera de la contribución de las "sociologías indígenas" a la sociología global sería a través de su reconocimiento como una alternativa teórico-metodológica para la expansión del universo ontológico del pensamiento sociológico contemporáneo.

PALABRAS CLAVE: Teoría social; Sociologías indígenas; Teorías y sociologías del sur; Sociología africana; Yoruba. 


\section{INTRODUÇÃO}

uase todos os debates sobre questões emergentes na sociologia contemporânea internacional ou transnacional citam os trabalhos de Akinsola Akiwowo associados ao tema das indigenous sociologies (Connell, 2007; Dufoix, 2018; Maia, 2017; Bringel e Domingues, 2017; Keim, 2008; Heilbron, 2014). Provavelmente por terem sido promovidos pela própria Associação Internacional de Sociologia (ISA), os estudos do sociólogo nigeriano inspirados na poesia oral ioruba se internacionalizaram, tornando-se uma porta de entrada para a consideração de potencialidades e limites de sociologias feitas nos países do Sul.

A hipótese principal aqui apresentada é a de que críticos e defensores dessa noção, em sua maior parte e com diferentes gradações, adotaram narrativas que mormente oscilam entre a constatação crítica de seu caráter ideográfico e limitado (Sztompka, 2011; Archer, 1991; Connell, 2007), de um lado, e a defesa geopolítica de sua importância por ter origem fora da Euroamérica (Keim, 2008; Go, 2015; Rosa, 2016), de outro. Os argumentos dessas duas ordens, segundo a posição aqui defendida, teriam deixado de lado a análise das implicações ontológicas da contribuição e seus possíveis efeitos epistêmicos (Adesina, 2002) para uma sociologia global, como procuraremos apresentar na parte final deste artigo.

A estrutura do texto busca combinar a reconstrução da história do debate africano sobre as sociologias indígenas, de sua recepção, e oferecer uma possível opção para sua interpretação, propondo uma alternativa teórico-metodológica para a expansão do fazer sociológico contemporâneo com base na reinterpretação do debate.

Na primeira parte, apresento os esforços de Akiwowo no contexto de abertura recente da sociologia, de modo geral, e da própria ISA, para contribuições não ocidentais ao mundo da teoria. Tal abertura esteve centrada no uso do dualismo entre os termos indígena e universal, ou, como fraseado por Adesina (2002), pela pretensão, mutuamente excludente, de uma forma ideográfica - usada de maneira derrogatória - ou nomotética - utilizada de modo positivo para descrever uma teoria geral - para a produção de conhecimento sobre a vida coletiva.

Na segunda parte, o texto propõe que as classificações das proposições de Akiwowo foram, no âmbito da ISA, apresentadas e lidas por meio de termos geopolíticos tradicionais, como ioruba, nigeriana e africana. Nessa seção, demonstro ainda que a recepção e a crítica internacional produziram mudanças nos próprios argumentos iniciais do autor.

$\mathrm{Na}$ terceira parte, chamo a atenção para a leitura hegemônica desses textos como uma busca por conceitos e definições estáveis e universais que deliberadamente rejeitam o desconcerto e o desconforto ontológico. 
Na quarta parte, seguindo os argumentos de Verran (2012), Law e Lin (2017) e De la Cadena (2015), defendo a postura teórico-metodológica de tomar o desconcerto como ponto de partida epistemológico para a interpretação deste debate.

0 texto se encerra buscando demostrar que os dualismos obliteram uma característica fundamental dessa contribuição que esteve contida nas proposições ontológicas derivadas do uso da poesia oral ioruba. Longe de serem só um produto da vida indígena nigeriana, as questões descritas em seus textos básicos sugerem uma possível forma teórico-metodológica mais geral: descrever e criar ontologias por meio de princípios desconcertantes e pouco permanentes, marcados pela multivalêcia e pela contradição coetânea. Diferente da própria forma como Akiwowo se apresentou durante parte do debate da ISA, sua contribuição talvez resida menos no conteúdo normativo da vida social e mais no modo inovador de lidar com propriedades ontológicas fluidas.

\section{AKINSOLA AKIWOWO E A CONSTRUÇÃO DE UMA REFLEXÃO SOBRE A SOCIOLOGIA AFRICANA}

omo primeiro passo para apresentar este debate, procurarei recuperar as pistas deixadas pela obra de Akiwowo para a construção de uma narrativa da sociologia africana

e, posteriormente, ioruba. Os primeiros textos traçáveis do autor para o debate internacional em inglês datam de década de 1960 e lidam com os dilemas das divisões étnicas e tribais no Estado nigeriano recém-formado. 0 texto intitulado "The Sociology of Nigerian Tribalism" soa como um representante clássico do tipo de intervenção sociológica que poderia ser encontrado em diversas partes do chamado sul global naquele momento.

Diante dos desafios locais para pensar a vida coletiva "moderna", a sociologia clássica europeia é convocada para fornecer coordenadas espaçotemporais nas quais se poderia classificar e hierarquizar a existência nacional africana ancorada em questões étnicas:

As there develops a common value system-an overriding national ideology-as jobs, money, and the means of acquiring them become accessible to all, tribalism, most likely, will give way to what Emile Durkheim calls the "collective unconscious", and a National Way of Life. (Akiwowo, 1964: 163)

No Brasil, com Florestan Fernandes; na Índia, com T. S. Madan; no México, com González-Casanova e Stavenhagen; ou na Malásia, com S. H. Alatas, a consolidação do Estado-nação moderno e seu sistema de valores se erguia como problema intelectual dominante nas ciências sociais naquele período. Nada seria mais adequado do que recorrer aos princípios analíticos e classificatórios usados nas matrizes coloniais que forjaram sua vida coletiva e 
colonizadora em torno do Estado. Compreendendo a sociologia no esforço universalista de produção científica da vida comum, não foi estranho para esses autores e para Akiwowo a fabricação metodológica global de parâmetros comparativos.

Por outro lado, pode ser que os nigerianos se dando conta dos absurdos e do preço alto do tribalismo busquem melhores soluções por meio da criação de instituições que facilitem a circulação elementos que ocupem os lugares de classe, status e poder, independentemente de sua religião, clã ou dialeto. (Akiwowo, 1964: 163)

Como apresentado nas passagens selecionadas, o tempo social nigeriano é demarcado pela presença ou não de certas instituições que incorporam o sentido da existência coletiva moderna. Nesse movimento, tornou-se comum a pesquisa que investiga a sucessão temporal de instituições capazes de produzir sentimentos, valores, referências coletivas e relações, exemplificados aqui no uso do contínuo religião/classe exposto por Akiwowo.

Essas instituições, portadoras dos valores modernos, foram cronologicamente classificados nas teorias sociológicas hegemônicas e tendem a ser apresentadas de forma sequencial como um referencial existencial/ontológico global (Archer, 1991; Sztompka, 2011). 0 centro analítico, focado na noção de Estado, seria a referência das existências consideradas modernas num mundo descrito como em processo de racionalização e secularização, seja na Europa, seja na Nigéria. Notemos, por exemplo, que nessas leituras aquilo que a sociologia associa institucionalmente à religião surge sempre como residual.

Num debate publicado em 1974 sobre as sociologias do terceiro mundo, Akiwowo aponta para os desafios de introduzir o contexto nacional na própria produção sociológica. Ele traz à tona o problema de intelectuais estrangeiros serem protagonistas do ensino de sociologia em seu país e sugere, entre outras coisas, que o valor então pago como salário a um estrangeiro permitiria a repatriação de dois nigerianos formados na Euroamérica para avançar as ciências sociais em seu país (Bengolea e Akiwowo, 1974: 417). Nesse debate compartido com intelectuais ocidentais, sugere brevemente uma política em favor da indigenização das ciências sociais.

Em artigo de 1976 em publicação da Organização das Nações Unidas para a Educação, a Ciência e a Cultura (Unesco), o autor se aproxima outra vez desse debate usando a noção de mente cativa em diálogo com texto de Alatas (1974) ${ }^{1}$ publicado anteriormente no mesmo periódico:

Não existem sinais aparentes para demonstrar que os cientistas sociais africanos, como raras exceções, deixarão de operar como mentes cativas, ou que as teorias e técnicas do modo de conhecimento ocidental internalizado por eles será substituído por outros também validos, mas autenticamente africanos (Akiwowo, 1976: 201) 
No mesmo texto, Akiwowo adverte sobre outro problema. 0 controle do Estado e seus burocratas sobre a produção sociológica nas universidades africanas tenderia a postergar indefinidamente a emergência de uma cultura acadêmica vibrante e independente (Idem: 201).

As contribuições posteriores de Akiwowo seguiram essa tendência, buscando refletir sobre o papel dos cientistas sociais e da sociologia na Nigéria e em toda a África (1980). Em capítulo de livro publicado também pela ISA, Akiwowo (1989), utilizando o trabalho do queniano Ali Mazrui (1978) sobre agenda dos intelectuais africanos, apresenta a definição de indigenização intelectual como um trabalho para reduzir a estrangeirização de ideias, conceitos, teorias e metodologias. Akiwowo defende, no entanto, que a noção deveria ser expandida para utilizar ideias, valores, conceitos, mitos, história oral e cosmologias com suas sensibilidades para experiências sociais africanas no lugar daquelas importadas, mesmo quando estas já não sejam vistas como estrangeiras pela comunidade acadêmica.

Segundo ele, a contribuição dessas fontes pouco usuais estaria mais próxima daquilo que Mazrui (1978) denominou em inglês de derationalization, ou seja, o desenvolvimento de um modo original e específico de embasar, argumentar e explicar fenômenos sociais. Para Akiwowo (1989), sociólogos africanos deveriam primeiro se apropriar das principais ferramentas da sociologia euro-americana - "endogeneizar", nas palavras de Hountondji (1997), para posteriormente desenvolver seu modo próprio de "desracionalizar" o modo hegemônico de narrar a vida coletiva.

Desracionalizar, em linhas gerais, significaria a possibilidade de estudar e descrever a vida coletiva fora do padrão lógico argumentativo que orienta a vida ocidental dominante na sociologia internacional. Nessa proposta, sugerida por Mazrui (1978), a forma narrativa estaria obrigatoriamente acompanhada da experiência existencial dos sujeitos. Nos termos do debate contemporâneo, que será trabalhado na parte final deste texto, ela estaria ligada a uma ontologia específica e a traços que se observam no uso do termo "sociologias indígenas" como apontado a seguir.

\section{A NOÇÃO DE SOCIOLOGIAS INDÍGENAS COMO SINÔNIMO INTERNACIONAL DE AFRICANO}

$\mathrm{P}$ aralelamente aos textos mais gerais sobre o lugar da sociologia na África, podemos observar, nas publicações traçáveis de Akiwowo no fim da década de 1970, a introdução do conhecimento ioruba como fonte de inspiração teórico-conceitual. Em artigo que surgiu primeiro como conferência, em 1979, e publicado em 1983, o nigeriano introduziu na sua sociologia a análise da poesia oral ioruba/lfa, que viria a ser o corpus analítico dos textos 
posteriores associados às sociologias indígenas no âmbito internacional. Em outro texto publicado em 1981, chamado "Ontology of personality and motivation", identifico pela primeira vez o uso da noção de ontologia para expandir questões teóricas em termos de uma teoria da motivação para a ação:

Aparentemente, apesar dos diferentes e intensivos estudos sobre a motivação nas sociedades ocidentais, nenhuma teoria ou explicação ontológica foi encontrada para responder pelos diversos aspectos do tema. E a possibilidade de que esta teoria venha a ser descoberta parece remota. (Morakinyo e Akiwowo, 1981:31)

Nesse texto, os autores procuraram elaborar uma noção contemporânea de pessoa na cosmologia ioruba que não operaria pelo dualismo mente/corpo para compreender a agência dos sujeitos, como nas versões ocidentais da sociologia e da psicologia.

Em suas publicações traçadas na pesquisa, o adjetivo indígena passa a ser sistematicamente utilizado quando os escritos passam a ser publicados pela ISA, na esteira do congresso realizado na Cidade do México em 1982. Naquela edição, Akiwowo apresentou o trabalho "Universalism versus Indigenization in Sociological Theory", na seção "Novos desenvolvimentos na teoria social". Na versão do próprio Akiwowo (1988), que publica a introdução ao número da International Sociology com tema de indigenization, o congresso no México havia sido marcado por protestos de estudantes que faziam traduções, sem permissão oficial, do francês e do inglês - únicas línguas oficiais da ISA na época - para o espanhol mexicano, em busca da ampliação da própria disciplina.

A partir daquele momento, o esforço de tornar relevantes as contribuiç̧ões de autores e autoras de fora da Euroamérica passa a se fazer presente na ISA e se reflete em publicações e discursos de seus presidentes com diferentes matizes (Archer, 1991 e Sztompka, 2011). É importante notar que, em 1982, F. H. Cardoso é eleito presidente da ISA e, em 1986, escreve a Introdução ao primeiro número da revista Internacional Sociology, criada pela instituição para publicar artigos de pessoas motivadas pelas suas próprias tradicionais nacionais e culturais (Cardoso, 1986: 1). 0 que não estava claro naquele momento era o lugar teórico das tradições culturais e nacionais na sociologia internacional.

Acreditamos que a presença e a promoção de Akiwowo a condição de embaixador africano no Comitê Executivo da entidade entre 1974 e 1982 tenham levado para dentro da ISA a ideia de internacionalizar por meio da noção de indigenização.

Se, em 1964, Akiwowo tendeu a encarnar os moldes sociológicos dominantes em seu tempo para descrever os dilemas nigerianos, uma década depois, o autor, ao se tornar a principal voz africana na ISA, iniciou a publicação de reflexões sobre possíveis características 
teóricas especiais das sociologias da região. Na passagem abaixo, ele revela desconforto com uma indesejável dependência conceitual das sociologias africanas e sua posição diante da produção universalista euro-americana.

Outro fator importante que dificulta a emergência de melhores paradigmas de sociedade na África é a complete dependência dos sociólogos em geral dos conceitos e categorias desenvolvidos para explicar a vida social europeia e americana. Assim estas últimas são tratadas como instrumentos universais para o conhecimento e explicação da vida social em várias sociedades africanas (1980: 5)

No mesmo texto, no entanto, como ressaltam Adesina (2002), Lawuwyi e Taiwo (1990) e Archer (1991), o autor oscila entre encontrar equivalentes dos termos "sociedade", "grupos sociais" e "processos sociais" da sociologia ocidental no vernáculo africano e encontrar elementos próprios que os diferenciariam da matriz ocidental.

Por que não utilizar conceitos africanos de sociedade, grupos sociais, processos sociais e semeIhantes, derivados de maneiras africanas de codificar a realidade, para chamar a atenção para outros elementos característicos na matriz disciplinar da sociologia? (Idem: 6)

Em 1986, o volume 4 do primeiro número da International Sociology traz o texto de Akiwowo "Contributions to the Sociology of Knowledge From an African Oral Poetry". Nele, o autor deixa de lado a metarreflexão sobre a sociologia na África para introduzir empiricamente a poesia oral ioruba como possível fonte conceitual e elemento de distinção epistemológica: "O artigo apresenta um numero de proposições indutivamente inferidas da doutrina da criação contida na poesia oral ioruba como um provável enquadramento teórico para a sociologia" (1986: 344).

De forma inovadora, pela primeira vez uma revista da ISA tinha cerca de metade dos textos da poesia oral ioruba Ayajo Asuwada traduzidos para o inglês e, ao fim, apresentava um glossário com 56 termos em ioruba. A inovação da forma e do conteúdo contribui para o propósito de Akiwowo de criar um provável quadro teórico que fosse mais adequado (nomotético) para compreender primeiro a vida coletiva ioruba e nigeriana e, depois, questões consideradas mais gerais: "Proposições que, esperamos, possam estimular o sério interesse, mesmo que crítico, de cientistas sociais nigerianos, em particular, e de antropólogos e sociológos em geral. (1986: 353).

Para isso, o autor retoma um argumento dos anos 1970 sobre a relevância da tradição oral no desenvolvimento das ciências sociais na África: "Entretanto, o modo de conhecimento das ciências sociais e sua difusão não deveriam estar confinados à cultura dos livros. Deveria ser possível apreender e difundir por meio das tradições orais de aprendizado que necesitam ser desenvolvidas na África e exportadas par o extrangeiro." (1979c :19). 
0 que pode ser observado é a projeção dos princípios de sociação da poesia ioruba para a formação conceitual e analítica apropriada para a África nos moldes vernaculares criticados por Adesina (2002), Lawuwyi e Taiwo (1990) e Archer (1991). Apesar de ter apresentado quatro anos antes um paper com esse nome no México, em nenhum lugar do texto encontramos o uso do termo "indígena". 2 Somente na Introdução ao número da International Sociology de 1988 é que o termo "indígena" 3 aparece e é definido usando uma citação de aula inaugural por ele proferida em 1978, na Nigéria: "A ideia é que a sociologia possa se beneficiar de ideias locais contidas na literatura oral africana para atenuar os riscos de depender completamente de conceitos e hipóteses ocidentais." (1988:160).

A noção de indigenização, num contexto de descolonização tardio, surge ali próxima daquela de endogenização desenvolvida posteriormente por Hountoundji (1997) para falar da dependência teórica africana. Para Akiwowo, indigenizar teria o alcance microteórico que serviria para explicar a vida coletiva local quanto a fatos sociais, ordem social ou realidades sociais (Idem). Como descrito, em 1989, num capítulo de livro feito também para a ISA, o autor se associa a Ali Mazrui (1978) na tentativa de uma definição mais precisa do processo de indigenização das ciências sociais.

Os textos de 1986 e 1988 foram seguidos por duas críticas feitas por autores nigerianos trazidas pela própria International Sociology em 1988 e 1990. 0 ponto central é a própria hermenêutica da poesia oral segundo diferentes perspectivas na Nigéria. Em termos gerais e ocidentais, estabelece-se uma controvérsia sobre termos que orientariam uma relação específica entre indivíduos e comunidades. Enquanto na versão de 1986 Akiwowo mencionava a necessidade de princípios explanatórios para lidar com ideias e noções contidas na poesia oral, nas críticas de Makinde (1988), Lawuwyi e Taiwo (1990) os termos em ioruba são tratados como conceitos.

Ao serem trabalhados nos moldes de conceitos sociológicos, a primeira conclusão é a de que faltaria precisão aos termos escolhidos por Akiwowo. É na crítica de Lawuyi e Taiwo, que ataca tanto Akiwowo quanto Makinde - o qual tentou esclarecer alguns termos usados por Akiwowo -, que reside o tema central que inspira o presente texto. Para os autores, não há precisão nos termos ioruba usados por Akiwowo, e isso, por definição, os tornaria não universalizáveis no debate sociológico internacional:

"O conhecimento não é apenas um fenomeno transcendente, mas também uma noção culturalmente delimitada que pode ser inutil para além do youruba ou das sociedades africanas" (Lawuyi e Taiwo 1990:71).

0 problema central dos argumentos apontado pelos colegas nigerianos de Akiwowo foi sua imprecisão, sobretudo quanto à descrição do princípio do asuwada que teria ao menos 
três sentidos diferentes em seus textos. Em resposta publicada na mesma revista em 1991, Akiwowo adota a noção de conceitos para falar dos termos da poesia ioruba e procura mostrar que não haveria tanta imprecisão em partes de seu argumento, pois o objeto seria uma hermenêutica de poesia oral. Em termos sociológicos mais gerais, o problema de Akiwowo reside em como tratar com precisão elementos que são constantemente produzidos e reproduzidos na oralidade.

\section{AKIWOWO SE MOVE COM A CRÍTICA}

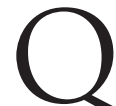

uase uma década depois, um novo texto de Akiwowo na Internacional Sociology retoma o debate com Lawuyi e Taiwo, dessa vez centrando a defesa da pertinência analítica dos termos em ioruba justamente por sua fuzziness. Valendo-se dos argumentos de Bart Kosko (1993) sobre o fuzzy thinking, Akiwowo passa a defender e a descrever a imprecisão ontológica como a característica fundamental dos termos ioruba e de sua sociologia indígena. Não haveria para o autor nigeriano estabilidade espaçotemporal na relação entre formas de sociação mais individuais e mais comunitárias, aos moldes de Weber ou Durkheim, por exemplo. Usando o termo consagrado por Fabian (1982), observamos uma aposta já tardia de Akiwowo na coetaneidade ontológica entre o individual e o comunitário como meio de lidar com a vida coletiva ioruba, que, nos termos sociológicos ocidentais, é imprecisa.

É possível depreender que o autor ainda busca, contraditoriamente, precisar o princípio geral do asuwada como algo que poderia ser universalizado para a sociologia global com um conceito único que abrangeria o coletivo e o individual. Nota-se aqui, mais uma vez, que o próprio Akiwowo oscilava nos seus argumentos, a depender do debate em que se envolvia - no âmbito da ISA, da Unesco ou dos debates nigerianos -, e que não conseguiu ir muito além da armadilha sociológica de provincializar a própria contribuição quando contestado em nível global.

Ao olhar de fora do debate que termina por desautorizar a noção de sociologia indígena, porém, no texto de 1999 a poesia oral foi de novo por ele mobilizada, a fim de afirmar dois pontos inovadores: a ambiguidade dos seres e a multivalência das realidades. Usando de outra narrativa oral ioruba para se engajar com a noção de fuzzines, o autor se alimenta das propagadas lições do sábio ou sacerdote Orunmila, que distribuía lições morais sobre a natureza processual, não linear e não rígida da existência ioruba. Aqui vejo pontos nos quais a teoria social em escala global poderia se inspirar e receber os efeitos deste trabalho com mais abertura. 


\section{ASUWADA COMO CONCEITO: A RECEPÇÃO GEOPOLÍTICA DA SOCIOLOGIA ESTABELECIDA}

$\mathrm{C}$

omo ressaltado, as contribuições de Akiwowo oscilam entra o uso da poesia oral ioru-

ba para constituir uma proposta mais radical de independência teórica da sociologia africana por vias epistemológicas e a busca conceitual por termos locais equivalentes àqueles consagrados pela sociologia hegemônica ocidental.

No âmbito internacional, as conexões de leitura e recepção de Akiwowo e seus textos, no universo de uma sociologia que tentava se tornar global a partir dos anos 1980, tiveram como principal efeito a redução de seus argumentos à noção de asuwada como equivalente de conceito sociológico. Foi apenas sobre a possibilidade de universalização de um termo classificado geopoliticamente como de origem indígena africana que sua contribuição foi posta à prova. $A$ iniciativa foi recepcionada na sociologia internacional, na melhor das hipóteses, com uma retórica exotizante e, não por acaso, confinada na armadilha da "sociologia indígena" e cobrada por não gerar conceitos e teorias gerais. Vejamos, por exemplo, como o trabalho de Connell (2007: 96) tentou abrir espaço hipotético para as chamadas sociologias do sul na África a partir dos trabalhos de Akiwowo: "Let's assume that I am trying to use the asuwada principle and the concepts of ajobi and ajogbe in my sociological research in Australia" (2007: 96).

Num capítulo inteiro de seu livro para reconstrução do pensamento social africano e em especial de Akiwowo, a autora vai buscar a precisão conceitual - já criticada por pares nigerianos nos debates da ISA - que garantiria sua circulação global. 0 mesmo tipo de leitura, mas com outro objetivo, pode ser observada na apreciação de Julian Go ao buscar promover as teorias do Sul e pós-coloniais na teoria social e na sociologia: "O conceito do Asuwada poderia ser a base para uma sociologia não baseada no ocidente"(2016: 148).

A expectativa de Connell e Go, ao considerar a possibilidade de testar a iniciativa de Akiwowo como um avanço teórico nos moldes como o centro faz - na própria definição da autora australiana -, era um conceito preciso ou utilizável na pesquisa aplicada, especialmente em outras partes do sul global - um conceito que gerasse comunicabilidade global que acaba por não acontecer em nenhuma das recepções aqui descritas.

Reed (2013) interpela criticamente o desenvolvimento do trabalho de Connell (2007) e, sobretudo, esse modo geral de abordar e interpretar os trabalhos de Akiwowo.

Connell lida com a sociologia Africana a partir de pressuposições extremamente gerais pressuposições reminiscentes, ou talvez utilizáveis com contraponto para, os Manuscritos Econômico-Filosóficos de 1844 que formam a espinha dorsal de tantos cursos de teoria clássica (2013:165). 
Para o autor, a expectativa positiva é criada apenas para diálogos no nível de teorias de longo alcance. Segundo ele, a busca ideal nesses casos deveria estar focada no que Merton classificou como teorias e conceitos de médio alcance, típicas da sociologia contemporânea. É preciso lembrar que o próprio autor havia classificado sua intervenção como microteórica (Akiwowo, 1988:160).

Para a própria Connell, a solução encontrada para os limites das translações conceituais gerais presentes na noção de asuwada levariam a seu abandono como possibilidade alternativa: "Eu não estaria assim usando uma sociologia indígena da Nigéria, mas construindo meu próprio sistema sincrético, o que faria pouco sentido para outras sociólogas tanto na Austrália quanto na Nigéria" (2007: 96).

Na perspectiva da autora, uma construção teórica com base nas concepções "indígenas" localizadas no tempo, na língua, na experiência e no espaço seria por demais limitada para compor um panteão teórico da sociologia global, porque encontraria barreiras culturais demasiado fortes.

Como sugerido na Introdução, em especial entre comentadores não africanos, a presença de Akiwowo e seus escritos é um gesto diplomático geopolítico no sentido mais tradicional do termo. Entre entusiastas e céticos, o termo "sociologias indígenas" foi e tem sido utilizado para demonstrar a capacidade ou a generosidade política de inclusão da África em debates globais e universais, por isso credencia mais quem o menciona politicamente do que seu autor. A apropriação de sua pesquisa e seu argumento, no entanto, são apresentados de forma a não contribuir para a reconsideração da dimensão histórico-espacial disciplinar centrada na Euroamérica nem para a ampliação de sua política teórica. Eles ocorrem limitados por aquilo que Keim (2008) chamou de "arena dominante de competição". Em suma, trata-se de um argumento que não avança na transformação do espaço ou da política nessa área de conhecimento, como sugere Latour (2016: 16) ao debater os limites da discussão geopolítica nas ciências sociais.

No âmbito da arena dominante dos debates teóricos, a única porta de entrada aparentemente possível seria por meio da introdução de conceitos com muita elasticidade e comunicabilidade para considerar desafios empíricos que não tenha um equivalente já estruturado em nosso corpus teórico disciplinar ocidental. A introdução da poesia oral e da existência instável ioruba colocam dois elementos distantes demais do centro normal da sociologia global. A falta de comunicabilidade dos termos ligados ao asuwada contribui, assim, para o desconcerto da audiência internacional em lidar com uma possível teoria social que seria não facilmente aplicável na pesquisa empírica. 
O próprio avanço conceitual proposto por Akiwowo (1989) em relação a Mazrui (1978), de desracionalizar as ciências sociais tendo como base ideias, valores, mitos, história oral e cosmologias, terminou reduzido apenas à sua dimensão conceitual. Na arena dominante do debate teórico da sociologia internacional, a qual o próprio Akiwowo e alguns de seus colegas nigerianos adentraram, não existiu espaço para inclusão significativa da oralidade, valores e experiências não lineares e racionalizadas nos termos euro-americanos.

Somente em seus leitores mais tardios e baseados no próprio continente, como Adesina (2002), Omobowale e Akanle (2017) e Ademoyo (2009), é que se vislumbra a inquietação por aprofundar os desafios epistemológicos presentes na proposta de Akiwowo. Nessa leva mais recente de intepretação, permanece a crítica ao risco de uma sociologia vernacular apontado por Archer (1991), mas acompanhado de um claro movimento de ressaltar a dimensão ontológica do contexto da pesquisa: "Há um compromisso ontológico na sociologia do conhecimento de Akiwowo que permite a explanação de suas ideias sobre a popósito, a socialidade humana, natureza e sociedade" (Ademoyo, 2009: 16).

Apropriando-se do termo "intervenção epistêmica", cunhado por Adesina (2002), Omobowale e Akanle (2017:49) recuperam o trabalho de Akiwowo procurando demonstrar que a noção de asuwada se encontra ancorada numa ontologia normativa específica que condiciona a ação no mundo em parâmetros pouco usuais na sociologia ocidental. Tendo a ontologia ioruba como base normativa, os textos sobre as sociologia indígenas ensejariam uma desejada "abertura epistêmica" para outras sociologias africanas e mesmo do sul global. Tal abertura seria uma alternativa concreta à dependência epistemológica da disciplina em relação às ontologias euro-americanas.

Enquanto os autores africanos acima buscam retomar essa abertura por uma volta aos princípios sistêmicos presentes na noção de asuwada, gostaria de sugerir que as saídas encontradas no texto de 1999 podem conter outra fonte de ampliação e abertura epistemológica. Ao ser interpelado a lidar com a noção de fuzzy, Akiwowo introduz com mais clareza a necessidade de levar em conta na sociologia a importância de lidar epistemologicamente com ontologias processuais não lineares ou rígidas. 0 desafio empírico de lidar com trânsitos ontológicos necessariamente imprecisos entre o bem e o mal, entre as existências físicas e metafísicas como parte do coletivo que chamamos de social, sugere uma oportunidade interessante para a disciplina em nível global.

Como ressalta Akiwowo no texto de 1999, a condição ontológica dos objetos e suas propriedades individuais mudam no decorrer de sua existência e de acordo com os coletivos nos quais são envolvidos. Sem abrir mão de sua linguagem sistêmica, o autor afirma que elas se adaptam segundo as mudanças nos propósitos gerais do asuwada. 
Gostaria de sugerir que, para além de uma definição conceitual do asuwada, o passo mais importante de Akiwowo foi lidar epistemologicamente com objetos específicos de realidades nas quais são transformados continuamente. Por meio da incorporação da oralidade, fonte por demais instável para a sociologia dominante, a transformação ontológica causa desconforto e desconcerto para a ciência social hegemônica.

\section{DESCONCERTO NA APROPRIAÇÃO DO DEBATE SOBRE A INSTABILIDADE ONTOLÓGICA}

noção de desconcerto - disconcertment, em inglês -, da forma como foi apropriada
nos debates da área dos estudos sociais da ciência (STS), fornece boas pistas para compreender os dilemas da produção e recepção do trabalho de Akiwowo. De modo específiCo, as contribuições de Verran (1999) e seus desdobramentos nas obras de Law (2004), Law e Lin (2017) e De la Cadena (2015) avançam na defesa de um lugar epistemológico/metodológico que considere o desconcerto empírico como um primeiro passo no avanço e na ampliação do escopo ontológico e, portanto, teórico de nossas disciplinas.

De forma ampla, considero que as experiências desses autores contribuem para a compreensão dos limites e dos efeitos que o leque limitado de ontologias (modernas) de que dispomos têm nos desdobramentos teóricos da sociologia contemporânea. 0 principal desses efeitos-limite seria o procedimento de criar e estabelecer hierarquia analítica na descrição de ontologias significativas. Para aquelas pouco controversas e produzidas como estáveis seria dedicado o centro, e partir dele seriam inseridas comparativamente ontologias dependentes, inferiores e imprecisas, seja no ocidente, seja fora dele.

Os trabalhos de Verran (1999, 2001 e 2012) são fundamentais na formulação do enunciado deste artigo, porque apresentam etnograficamente o encontro entre uma pesquisadora ocidental e seus conceitos com o mundo ontológico ioruba presente na teoria de Akiwowo. Na Nigéria, ela exerceu a supervisão do ensino de matemática, e com base nessa experiência descreve o processo de lidar cotidianamente com um método de ensino supervisionado por brancos, mas que lidava com o modo cotidiano e adaptativo ioruba de quantificar.

Em Science and African Logic (Verran, 2001), a própria autora constata sua dificuldade em lidar, enquanto esteve na Nigéria, na prática do ensino de matemática, com sua própria experiência desconcertante. Apesar do desconcerto ter sido por ela corporificado, a experiência em si não teria a princípio resultado na produção teórica sistemática de um modo inovador de ensino abarcando meios de quantificar ocidentais e ioruba. É com base numa reflexão a posteriori que encontramos sua invocação para a prática teórica de "cultivating epistemic 
disconcertment" (2012: 143). Ou seja, sua demanda pela incorporação do desconcerto num momento anterior ou coetâneo da análise.

Em seu livro After Method (2004) e em textos mais recentes escritos com o colega taiwanês Wen-yuan Lin, John Law sugere que uma possível solução para o dilema descrito por Verran é tornar a própria experiência empírica desconcertante um ato performativo de teoria. Cultivar o desconcerto seria uma chave teórico-metodológica para evitar a mera reprodução das ontologias dominantes na teoria social.

Nós sugerimos que explorar as origens do desconcerto desta forma e os tornar discursivamente confiáveis, é também performativo. Nossa conclusão é que o cultivo do desconcerto é uma sensibilidade ou ferramenta crucial que contribui diretamente para irmos além da metafísica, das subjetividades, e para formas organizacionais menos diretamente institucionais que reproduzem as tradições ocidentais hegemônicas de conhecimento (2011: 138)

A noção cunhada por Verran ganha contornos específicos quando se torna parte da construção de uma narrativa sobre a política da terra nos andes peruanos e do dualismo que marcou as análises que separaram a política indígena da política camponesa. Em Earth Beings, De La Cadena (2015) retoma a noção de Verran e acrescenta:

Assim, ao invés de reconhecimento, o desconcerto epistêmico gera perplexidade e tem o potencial para nos fazer pensar desafiadoramente o quê e como conhecemos. Não é raro que o desconcerto seja minimizado; aquilo que o provocou é considerado negado, tornado banal ou tolerado como uma crença. Mesmo que estas atitudes não representem uma conspiração política, elas anunciam uma política ontológica que define o real (ou o possível). (2015: 276).

Para a autora, o ponto central é a pratica de convivência com as ontologias que causam perplexidade por meio da tolerância à sua existência, sem, no entanto, admitir que tal existência possa ter implicações sobre o modo pelo qual a sociologia hegemônica entende 0 mundo moderno e seus objetos. No caso do Peru, a relação indígena com a terra foi reduzida aos termos ocidentais da noção campesinato e não teria ampliado o entendimento da relação entre política e natureza, por exemplo. Assim como o trabalho de Akiwowo que foi limitado ao asuwada.

Este é ponto central do que eu gostaria de chamar de "política ontológica" hegemônica na teoria social contemporânea. Uma política que permite a presença do estranho pela tolerância, como o bom e necessário selvagem, sem que, no entanto, demonstre qualquer engajamento pelo trabalho teórico-metodológico de sua construção e por sua ampliação do que seria real ou possível. 
É justamente essa ampliação, movida pelo desconcerto, que daria lugar à formação por parte de pesquisadoras/teóricas de terceiras categorias/ontologias multivalentes que não seriam simplesmente traduzidas de um lugar a outro. Para evitar a abertura de um debate vazio sobre o verdadeiro sentido de um termo, De la Cadena se apropria da noção forjada por Viveiros de Castro (2004) de um método de "equivocação controlada" para marcar que desentendimentos e equívocos são a marca das diferenças e das heterogeneidades. A equivocação seria elemento metodológico central para qualquer análise que tenha como base a oralidade e suas instabilidades no tempo e no espaço.

Em vez de aceitar tomar a imprecisão e a heterogeneidade como fonte para um debate sobre os limites ontológicos de conceitos sociológicos, os leitores estabelecidos preferiram apostar na manutenção da precisão conceitual, construindo um flanco contínuo para a desconstrução de inovações vindas fora da desejada existência moderna homogênea.

\section{CONCLUSÃO: DESCONCERTO ONTOLÓGICO COMO LIMITE DA TEORIA}

omo apontam num texto recente Omobowale a Akanle (2017), se as tentativas de

Akiwowo não tiveram nenhuma recepção concreta na sociologia internacional que fosse diferente da exotização, na própria Nigéria elas também não produziram efeitos e sequer são ensinadas. 0 ponto levantado pelos autores é muito simples: na Nigéria ou no Brasil, o debate não é tido como teoricamente relevante, "talvez porquê esteja ainda por ser 'autenticado' ou aceito pela ciência social dominante na academia do mundo desenvolvido" (2017: 45).

Com o tema da autenticação, que, no caso da International Sociology, operou em duas vias - nacional e internacional -, retomamos a questão geral deste texto. A sociologia global em seus rincões teóricos preza pela aplicação conceitual e pela precisão de suas definições, condições básicas para que qualquer estudo tenha comunicabilidade e ingresse no panteão sem provocar desconcerto e desorientação no seu modo de argumentação.

Os trabalhos sobre as sociologias indígenas lançados internacionalmente pela ISA por meio das publicações de Akiwowo comungaram dessas premissas e, durante a maior parte do tempo, procuraram ser aplicáveis e precisos num contexto específico - motivo pelo qual foi cobrado localmente, na ISA e nos fóruns internacionais. Como o próprio autor enuncia, um dos dilemas estava em como estabelecer uma relação entre desafios indígenas e universalismo teórico desejado pelo modo argumentativo da arena dominante, enquanto o outro foi a incorporação da poesia oral como fonte. 
Um ponto importante é que a literatura tem chamado de limites do universalismo apontando para as escassas condições de comunicabilidade existencial como fonte primária do desconcerto. 0 que procuro sustentar é que persiste um dilema sobre as ontologias - do meu ponto de vista limitadas ao ocidente - nas quais deve se assentar a disciplina. 0 processo de produção e circulação que consagrou certos autores e teorias como hegemônicos impele ao bloqueio da comunicação bidirecional e à promoção de novas ontologias como ampliação de nosso escopo analítico.

As ontologias indígenas ou não hegemônicas são produzidas como irrelevantes porque seus efeitos na intepretação da orientação da ação no mundo moderno são considerados também irrelevantes para quem produz teoria contemporânea. Uma boa parte da teoria que lemos e produzimos não se submete ao desconcerto ontológico, porque não encontra, teórica e empiricamente, outros mundos vividos que não sejam "modernos". Como tenho ouvido em alguns debates, nós, sociólogos, seríamos todos ocidentais/modernos, por isso nos interessaria descrever os efeitos deste mundo.

Discordando desse tipo de argumento, este texto tem posição próxima àquela de Go quando afirma que o projeto das sociologias indígenas "não é somente pela inclusão; por somente ampliar o escopo. É sobre diálogo, se não substituição ou trasncendência" (2015:149).

Em termos da análise específica, defendo que o universalizável para a sociologia não seria algo como o princípio conceitual do asuwada - se fosse feito aplicável -, mas a inovação em considerar a instabilidade ontológica da oralidade como princípio metodológico organizador da teoria social. Mesmo que Akiwowo tenha tido que recorrer aos termos de Kosko para dar legitimidade a seu texto, é na sua descrição da poesia oral ioruba que residiria sua intervenção epistêmica. A depender do contexto, da situação e das crenças de quem as descreve, uma existência pode ganhar e perder propriedades que a tornem inclusive contraditória. Mais do que o conceito em si, é a possibilidade epistemológica e metodológica de lidar com a multivalência e o trânsito processual ontológico que torna a proposta das sociologias indígenas relevantes num projeto global de expansão.

A expansão ontológica, nos moldes sugeridos por Cadena (2015), contribuiria justamente para aquilo que Adesina (2002) chamou de intervenção epistêmica. Voltando aos termos de Mazrui (1978), citados por Akiwowo, a introdução de novas formas de existência em transformação e contínua equivocação implicaria, por definição, o desenvolvimento de um modo original de descrever e organizar o mundo social. Avançando no diálogo entre essas duas tradições, a desracionalização seria, no contexto da sociologia ioruba, o desenvolvimento de mode of gathering (Law, 2004) inovador que desafie os conjuntos ou os coletivos dos quais a sociologia atualmente dispõe. 
Para encerrar, defendo aqui a posição de que o desconcerto ontológico exemplificado pelos usos e pelas leituras das sociologias indígenas não deve ser lido somente por sua aplicabilidade local, mas justamente pelo que ele poderia afetar nos desenvolvimentos futuros da teoria sociológica. Longe de ser o único modo de fazer ciências sociais, cultivar o desconcerto (Verran, 2012: 143) pode ser um caminho interessante para a produção ampliada de teoria num mundo que conhecemos ainda muito pouco.

\section{NOTAS}

1 "O que acontece é um mero transplante do pensar. Novamente, eu não sugiro uma simples adaptação simples de técnicas e metodologias, mas do aparato conceitual, dos sistemas de análise e da seleção dos problemas" (Alatas, 1974: 695).

2 É importante notar que no número do International Social Science Journal de 1976, no qual figura um dos textos de Akiwowo, outro autor nigeriano já utilizava os termos indigenous e indigenization.

3 No texto de 1989, Akiwowo cita um manuscrito não publicado de 1985 intitulado "Indigenous and universal perspectives in theoretical sociology".

\section{REFERÊNCIAS BIBLIOGRÁFICAS}

ADESINA, Jimi O. Sociology and Yoruba Studies: epistemic intervention or doing sociology in the "vernacular"? African Sociological Review/Revue Africaine de Sociologie, v. 6, n. 1, 2002.

ADEMOYO, Adeolu. Purpose, human sociality and nature in Akiwowo's sociology of knowledge: a realist interpretation. African Sociological Review/Revue Africaine de Sociologie, v. 13, n. 2, 2009.

AKIWOWO, Akinsola. The Sociology of Nigerian Tribalism. Phylon, n. 162, 1964.

. The Role of Social Scientists in Africa: Further Reflections. International Social Science Journal, v. 28, n. 1, 1976.

Ase: the concept of authority. Unpublished monograph, 1979a.

. An African paradigm of society. Unpublished monograph, 1979b.

. Textbooks and Materials for Africa. International Social Science Journal, v. 31, n. 1, 1979c.

. Trend report: Sociology in Africa today. Current Sociology, v. 28, n. 2, 1980.

. Ajobi and Ajogbe: variations on the theme of sociation. Ife: University of Ife Press, 1983.

. Understanding interpretative sociology in the light of oriki of Orunmila. Journal of Cultures and ideas, v. 1, n. 1, 1983b.

. Universalism and indigenisation in sociological theory: Introduction. International Sociology, v. 3, ก. 2, 1988 . 
Building national sociological tradition in an African subregion. In: GENOV, Nikolai. National traditions in sociology. London: Sage, 1989.

Responses to Makinde/Lawuyi and Taiwo. International Sociology, v. 6, n. 2, 1991.

Indigenous sociologies: extending the scope of the argument. International Sociology, v. 14, n. 1, 1999,

ALATAS, Syed Hussein. Captive mind and creative development. International Social Science Journal, v. 26, n. 4, 1974.

ARCHER, Margaret S. Sociology for one world: unity and diversity. International Sociology, v. 6, n. 2, 1991.

BENGOLEA, R. Perrotta; AKIWOWO, Akinsola. Problems in peripheral regions. International Social Science Journal, v. 26, n. 3, 1974.

BRINGEL, Breno; DOMINGUES, José M. Social Theory, Extroversion and Autonomy: Dilemmas of Contemporary (Semi) Peripheral Sociology. Method(e)s -African Review of Social Sciences Methodology, v. 2, n. 1-2, 2017.

De la CADENA, Marisol. Earth beings: Ecologies of practice across Andean worlds. Durham: Duke University Press, 2015.

CARDOSO, Fernando H. Foreword. International Sociology, v. 1, n. 1, 1986.

CHAKRABARTY, Dipesh. Provincializing Europe: Postcolonial Thought and Historical Difference-New Edition. Princeton: Princeton University Press, 2009

CONNELL, Raewyn. Southern theory: Social science and the global dynamics of knowledge. London: Polity, 2007.

DUFOIX, Stephane. Coming to Terms with Western Social Science Three Historical Lessons from Asia. Journal of Glocal Studies, n. 5, 2018.

GO, Julian. Postcolonial thought and social theory. Oxford: Oxford University Press, 2016.

HEILBRON, John. The social sciences as an emerging global field. Current Sociology, v. 62, n. 5, 2014.

HOUNTONDJI, Paulin (Ed.). Endogenous knowledge: Research trails. Oxford/Dakar: African Books Collective, 1997.

KEIM, Wiebke. Social sciences internationally: The problem of marginalisation and its consequences for the discipline of sociology. African Sociological Review/Revue Africaine de Sociologie, v. 12, n. 2, 2008.

LAW, John. After method: Mess in social science research. London: Routledge, 2004.

; LIN, Wen Y. Provincializing STS: Postcoloniality, Symmetry, and Method. East Asian Science, Technology and Society - An International Journal, v. 11, n. 2, 2017.

LAWUYI, Olatunde B.; TAIWO, Olufemi. Towards an African sociological tradition: a rejoinder to Akiwowo and Makinde. International Sociology, v. 5, n. 1, 1990.

MAIA, João Marcelo Ehlert. Além da pós-colonialidade: a sociologia periférica e a crítica ao eurocentrismo. Cadernos de Estudos Culturais, v. 5, n. 9, 2017.

MAZRUI, Ali Al'Amin. Political values and the educated class in Africa. Los Angeles: University of California Press, 1978. 
MAKINDE, Moses A. Asuwada principle: An analysis of Akiwowo's contributions to the sociology of knowledge from an African perspective. International Sociology, v. 3, n. 1, 1988.

MORAKINYO, Olufemi; AKIWOWO, Akinsola. The Yoruba ontology of personality and motivation: a multidisciplinary approach. Journal of Social and Biological Structures, v. 4, n. 1, 1981.

OMOBOWALE, Ayokunle; AKANLE, Olayinka. Asuwada epistemology and globalised sociology: challenges of the south. Sociology, v. 51, n. 1, 2017.

PAYNE, M. W. Akiwowo, orature and divination: approaches to the construction of an emic sociological paradigm of society. Sociological Analysis, v. 53, n. 2, 1992.

PICKERING, Andrew. The ontological turn: Taking different worlds seriously. Social Analysis, v. 61, n. 2, 2017.

REED, Isaac. Theoretical labors necessary for a global sociology: Critique of Raewyn Connell's Southern Theory. In: GO, J. Decentering social theory. London: Emerald Group Publishing Limited, 2013.

ROSA, Marcelo C. Sociologies of the South and the actor-network-theory: possible convergences for an ontoformative sociology. European Journal of Social Theory, v. 19, n. 4, 2016.

SZTOMPKA, Piotr. Another Sociological Utopia. Contemporary Sociology, v. 40, n. 4, 2011.

VERRAN, Helen. Staying true to the laughter in Nigerian classrooms. The Sociological Review, v. 47, 1999.

Science and an African logic. Chicago: University of Chicago Press, 2001.

. Engagements between Disparate Knowledge Traditions: Toward Doing Difference Generatively and in Good Faith. In: GREEN, Lesley. Contested Ecologies: Dialogue in the South on Nature and Knowledge. Cape Town: HSRC Press, 2012.

Viveiros de CASTRO, Eduardo. Perspectival anthropology and the method of controlled equivocation. Tipiti - Journal of the Society for the Anthropology of Lowland South America, v. 2, n. 1, 2004. 